\title{
ASSESSING THE MODERATING ROLE OF EDUCATIONAL QUALIFICATION IN JOB SATISFACTION AND TURNOVER INTENTION RELATIONSHIP OF BASIC SCHOOL TEACHERS: EVIDENCE FROM NORTHERN GHANA
}

\author{
Abukari $^{1}$ K. A. \& Alhassan $^{2 *}$ I. \\ ${ }^{1}$ Academic Affairs Section, University for Development Studies, Tamale, Ghana. \\ ${ }^{2}$ Human Resource Planning and Research Unit, University for Development Studies, Tamale, Ghana \\ *Corresponding Author Email: ibrahim.alhassan@uds.edu.gh
}

\begin{abstract}
The emphasis on Educational Qualifications (EQ) of employees, the demand for skilled labour and the professionalization of occupational structure of teachers in general, have created a dilemma for employers and school authorities in retaining their competent and experienced staff and meeting their job needs on one hand, and increasing pressure to release them for higher educational experience on the other. This paper examines the moderating role of teachers' EQ in their Job Satisfaction (JS) and Turnover Intention (ToI) relationship in the Tamale Metropolis of the Northern Region of Ghana. The proposed model was evaluated based on valid data from 116 teachers obtained from a cross-sectional survey. To confirm whether or not EQ will moderate the JS and ToI relationship, a process macro (Hayes, 2018 v. 3.4) was run with mean cantering and 5000 bootstrapping. Regression Analysis was employed to determine the relationships proposed in the study. The results show a significant but inverse relationship between JS and ToI of teachers in the Metropolis. However, the EQ moderator function in JS and the ToI relationship was not supported. It was also found that Teachers' EQ had no significant effect on their ToI in the Metropolis. Empirically, the study extends our understanding of the constructs discussed. The paper also discusses some managerial implications, and because there were some contextual limitations, directions are also provided for future studies.
\end{abstract}

\section{Keywords: Employee, Educational Qualification, Job Satisfaction, Moderating Role, Turnover, Intention}

\section{Introduction}

Throughout history, job forms an essential part of human endeavour. Thus, an individual's choice of a job can inform his/her worldview, and add meaning to his/her existence. Conversely, a poorly selected job can lead to mediocrity and a low standard of life. Without a doubt, teachers are the most priceless asset in building a nation's educational and literacy base. Their emotional feelings and reactions towards their job and job situations may not only influence or determine their intention to leave or stay in their profession but also the quality of educational and other worthwhile knowledge they impact on students.
The emphasis on the Educational Qualification (EQ) of employees, the demand for skilled labour and the professionalisation of the occupational structure of teachers, in general, have created a dilemma for employers and school authorities in retaining their competent and experienced staff and meeting their job needs on one hand, and increasing pressure to release them for higher educational experience on the other. This is critical especially, at a time of alarming attrition of teachers in Ghana, and the growing global concern for the public sector to retain their experienced 
staff (Wright \& Davis, 2003; Cobbold, 2015; Sottie, 2019).

Available research evidence indicates that about 7,000 to 10,000 teachers in the public sector in Ghana leave their profession annually in Ghana, exacerbating the national problem of studentteacher ratio deficit (Ghana National Association of Teachers [GNAT] and Teachers and Educational Workers Union [TEWU], 2009; Sottie, 2019). Whilst recognizing the effect of job satisfaction (JS) on the high rate of teacher attrition, the report of the Ghana National Association of Teachers (GNAT) and the Teachers and Educational Workers Union (TEWU) indicates that about $90 \%$ of teachers in Ghana will quit their job for further EQ. Further EQ, especially in the public sector, may guarantee promotion and other work side rewards which in the long run leads to JS.

Much so, the JS of employees has been empirically proven to be a significant predictor of their Turnover Intention (ToI) by a large body of scholarship in various professions and cultural diversities (Ali, 2008; Aydogdu \& Asikgil, 2011; Finster, 2013; Chen et al., 2014; Reukauf, 2018; Ekabu, 2019). At a minimum, a study on teachers' JS and their ToI will provide an important diagnostic assessment of their willingness to quit or remain in their current profession in the Tamale Metropolis of the Northern Region of Ghana.

Again, the findings of this study will provide important feedback to employers and policymakers alike, about teachers' cognitive evaluation of their job and job situations, as well as how the desire of teachers to seek higher education affects their satisfaction and intentions to leave the Ghana Education Service (GES). Such feedback will be useful for planning purposes as well as future policy reforms in teacher study leave and engagement policies in the Public Educational Sector (PES). It can also serve as a criterion for improving the status quo, in terms of corporate behaviour and culture about teachers' working conditions at the GES. This is boldly mentioned because the JS of teachers, their ToI and their desire for additional EQ have been a topic of great concern for employers and stakeholders in the PES in Ghana (GNAT \& TEWU, 2009; Sottie, 2019).
Conspicuously, this points to a potential interaction between teachers' EQ on one hand, and their JS and ToI relationship, on the other. In other words, of what impact does teachers' EQ have on their JS and ToI relationship? As academically invoking as this question may seem, the interactive relationship between the three variables (EQ, JS, and ToI) has not been adequately explored; particularly, in the Ghanaian research landscape. Thus, the main objective of this study is to examine the moderating role of teachers' EQ in their JS and ToI relationship. The specific objectives are to:

a. Determine the level of teachers' satisfaction with their teaching job in the Metropolis.

b. Determine whether or not teachers in the Metropolis have some level of intention to quit their job.

c. Compare the JS level of the teachers in the Metropolis with their intention to quit the teaching job.

\section{Literature Review}

\section{Job Satisfaction}

Employees' JS has been widely studied by scholars across diverse disciplines. To a large extent, it is the most widely studied construct in the field of industrial and organizational psychology. This is evidenced by the volume of scholarly works on the construct since the mid1970s (Spector, 1985; Macdonald \& Maclntyre, 1997). The term JS is not a recent parlance in Human Resource Management (HRM) practice. It was initially propagated by Robert Hoppock (1935). According to Hoppock in his book titled "Job Satisfaction", the term, JS refers to any combination of psychological, physiological and environmental circumstances that cause a person to sincerely say I am satisfied with my job. This definition suggests that employee JS measures the extent to which an individual employee is happy with his or her job or job situations, and how that translates into achieving desired job values and personal goals. In view of this, JS can be an important indicator of how employees feel about their jobs; and a predictor of work behaviours such as organizational citizenship, absenteeism and 
intention to quit. JS is the pleasurable emotional state that results from the achievement of job values (Cronley \& Kim, 2017). It represents an interaction between an employee and his or her job or job environment by gauging the (mis)match between wants and expectations from the job, and what the employee feels $\mathrm{s}(\mathrm{he}) \mathrm{has}$ received (Wright \& Davis, 2003) of which s(he) expects to promote his/her happiness in life and to support $\mathrm{him} / \mathrm{her}$ to function as a social being. In general, employees are said to be satisfied with their jobs when there is a pleasant outcome between the value expectations of their job and the existing job realities.

One of the main preambles for the study of JS was the Hawthorne studies. These studies (1924-1933), credited, primarily, to Elton Mayo of Harvard Business School, sought to find the effects of various conditions (mainly recognition and/or observation) on worker-productivity other than wages. These studies ultimately showed that innovative changes in work situations temporarily increase employee productivity (called the Hawthorne effect). It was later discovered that the increase in the productivity did not result from the new conditions, but from the knowledge of being observed. This finding provided solid evidence that people work not only for payment but for other purposes. This new thinking paved the way for researchers to carry out investigations into other factors that influence employees' JS.

Therefore, it is safe to say that other factors determine the JS of employees in addition to payment. However, scholars in the JS literature are divergent in their views when discussing these factors. This is typified by the fact that different pundits in the people management fraternity, both past and present, have carved different but competitive theories to explain motivation in the workplace and how one can influence the JS of employees. Prominent among these experts include Abraham H. Maslow of the hierarchy of needs theory, Frederick Herzberg of the hygiene theory or two-factor theory, McClelland of the theory of needs fame, Victor Vroom of the theory of expectancy, Douglas McGregor of theory $\mathrm{X}$ and theory $\mathrm{Y}$, and Equity Theory credited to Stacy Adam. These theories are generally classified into enthusiastic behaviour, hygiene factors, managerial responsibility, and workplace theories; and all have a common purpose of motivating and influencing employees' JS; to reduce employee ToI.

\section{Turnover Intention}

Like JS, ToI has been part of discussions in HRM literature since the early 1920s. It is reported by Peter et al. (2017) that the first empirical turnover study was published by Bill (1925). In his study, Bill (1925) showed that clerical workers more often quit their jobs if their parents were professionals or small business owners than those whose parents worked in unskilled or semi-skilled jobs (Peter et al., 2017). To date, ToI has become a relevant construct in industrial and organisational management studies that, over the years, has enjoyed volumes of discourse in literature and hours of discussions in HRM workshops and conferences globally. Perhaps the reason for this increased scholarship effort directed towards the study of the construct is as a result of the fact that no organisation is interested in losing its experienced and competent employees. The concept (ToI) has also assumed a relevant place in the very complex modern occupational environment, perhaps because of its direct link to actual turnover and its associated cost to organisations (Finster, 2013). Employee ToI can be defined as the likelihood of an employee leaving the current job he/she is doing (Chittipa, Phattarapon, \& Kijboonchoo, 2012). In other words, it is simply the innate plan of employees to voluntarily leave their organisations. Employee turnover has significant costs and negative consequences for any for-profit organisation; and therefore, as reiterated earlier, ToI is important to organisations and their leaders because of the costly nature of recruiting, hiring and training new employees (Cho \& Lewis, 2012).

Multiple factors have been cited in the literature as being the drivers of employees' ToI. For example, Quan and Cha (2010) reported that past turnover behaviour is a strong predictor of future ToIs, and that age, education, work experience, salary, past turnover behaviour and work hours are functional in the ToIs formulation. Furthermore, whilst investigating the determinants of ToI among employees, the findings of Arshad and Puteh 
(2015) revealed that only two factors, namely, available work alternatives and work-life balance, have a significant impact on ToI among employees. However, Pienaar, Sieberhagen and Mostert (2007) cast a different opinion by indicating that the most significant predictor of ToI is JS.

\section{Relationship between Job Satisfaction and Turnover Intention}

Although several factors have been cited, as earlier on indicated, as factors that encourage an employee to leave his/her present job, JS is the most frequently cited as a significant predictor of an employee's intention to quit or keep his/her job; suggesting that an employee will stay with his/her present job if (s)he is satisfied with it; or, an employee forms an intention to quit or quits his/her current job if (s)he is not satisfied with the job. Findings of several studies (e.g. Tian-Foreman, 2009; Pienaar, et al., 2007; Cherng \& Chieh-Peng, 2006; Prasadini \& Gamage, 2013; Nazim \& Qadar, 2008) have favoured this view. Literature has considerable documented evidence that strongly supports the existence of a relationship between JS and ToI, the former being a significant predictor of - and varies inversely as - the latter.

\section{Relationship between Job Satisfaction and Turnover Intention of Teachers}

There have been volumes of documented empirical literature on the relationship between teachers' JS and their ToI at various educational levels in many different cultural contexts. For example, Finster (2013) found a significant and negative relationship between JS and ToI of teachers in the United States of America, which further predicted their actual turnover. Among private-sector college teachers in Pakistan, Ali, (2008) found a significant association between JS and ToI. This agrees with Mburu's (2015) findings that indicate that teachers who are dissatisfied with their jobs planned to quit. This view has also found acceptance in the research effort of Nazim and Qadar (2008) when their findings indicated that teachers' JS (satisfaction with payment, promotion and security) was found to have a strong but negative relationship with their ToI.
At the local level, similar findings have been reported by Appiah-Agyekum, Suapim, \& Peprah, (2013) in the Kumasi Metropolis of the Ashanti Region of Ghana, and Agomah, (2016) in the Bolgatanga Municipality of the Upper East Region of Ghana, where a negative relationship was found between teachers' JS and their ToI. Furthermore, in their study to investigate the influence of motivation and JS on teachers' intention to quit their job in public senior high schools in the Tamale Metropolis, Kosi et al. (2015) reported that JS made a negative contribution to the intention to quit. Thus, the study states its first hypothesis as:

\section{1. $H_{1}$ : There would be a significant but inverse relationship between JS and ToI of teachers in the Tamale Metropolis.}

\section{Education Qualification Moderates Job Satisfaction and Turnover Intention Relationship}

Often, the desire for higher EQ for purposes of gaining promotion at the workplace becomes a major factor in informing employees to quit their jobs; especially if an organisation's status promotes staff capacity-building. Indeed, employees with higher EQ, all things being equal, will tend to be loyal, committed and satisfied with their jobs and their organisations than those with lower EQ. Perhaps, this is because higher EQ is commensurate with higher pay, especially in the public sector, and so it is no surprise when the GNAT and TEWU (2009) report indicates that about $90 \%$ of teachers in Ghana will give up their job for further EQ.

In a study to compare the level of JS of three employee groups in a multi-campus public university in northern Ghana, Abukari et al. (2019) found that the administrators' group of the University staff had the highest JS, followed by teaching staff and then senior staff. The researchers further acknowledged that their findings were in alignment with normal organisational behaviour and work culture where employees with low EQ and hence low ranks and remunerations, and are found at the bottom of the job hierarchy are expected to be less satisfied with their jobs than those with higher EQ and ranks, especially in the Ghanaian public sector. 
Based on this finding, it is safe to conclude that the higher the EQ of an employee, the more likely $\mathrm{s}($ he) will be satisfied with his/her job and may, therefore, build citizenship; and/or the lower the EQ of an employee, the less likely s(he) will be satisfied with his/her job and may, therefore, form intention to quit, all other things being equal. Therefore, it seems reasonable that JS and ToI relationship should be moderated by EQ. Thus, the second and third hypotheses of the study are affirmed:

$H_{2}$ : Teachers' EQ would have a significant effect on their ToI in the Tamale Metropolis.

$H_{3}$ : Teachers' $J S$ and their ToI would be moderated by their EQ in the Tamale Metropolis.
Despite the huge volumes of literature on this subject, as evidenced in the foregoing discourse, there is still a literature vacuum on whether teachers' EQ will moderate their JS and ToI relationship at the basic school level in the Tamale Metropolis. Moreover, findings of prior studies on teachers' JS and ToI cannot be generalized; culturally and contextually. Therefore, the present study seeks to extend the discussion in the literature by examining whether or not teachers' EQ will moderate their JS and ToI relationship at the basic school level in the Tamale Metropolis. Therefore, the study was framed in the conceptual model shown below:

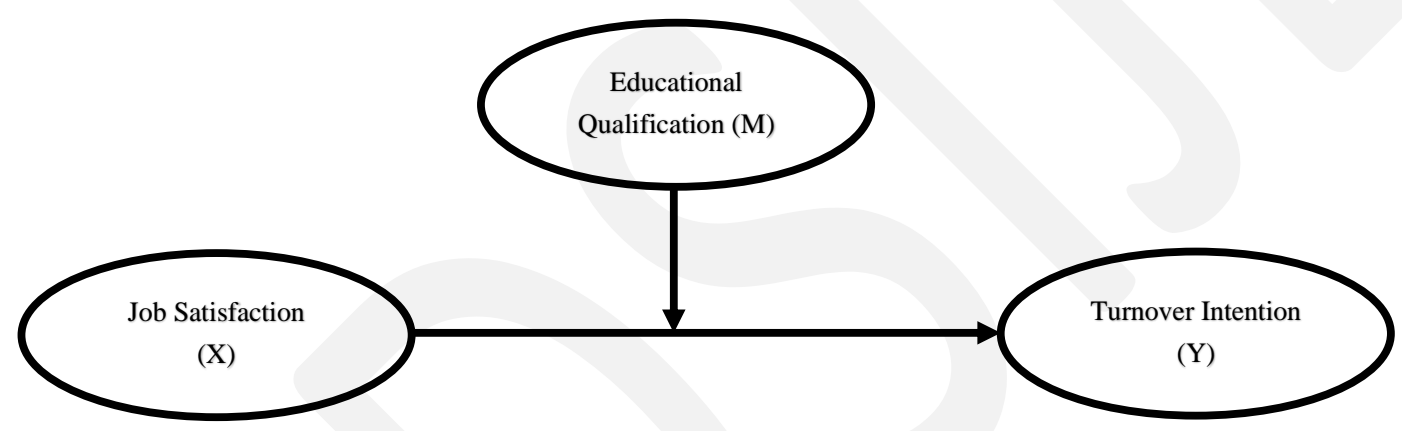

Figure 1. Conceptual Model

Source: Authors' Elaboration

Conceptually, the diagram shows how the relationship between job satisfaction $(X)$ and turnover intention $(\mathrm{Y})$ is influenced by educational qualification $(\mathrm{M})$.

\section{Methods}

\section{Study Setting and Sample}

Twenty-one public sector basic schools in the Tamale Metropolis were conveniently selected to participate in the study. The study selected teachers from only public schools because the researchers think that the findings of the study will be beneficial to the government with respect to the management of teacher professional and academic advancements. Besides, the study was conducted

at a time that there was much discussion on the decline of the education system in Ghana. In total, 150 copies of a questionnaire were distributed to professional and non-professional teachers in the selected schools. A sample of one hundred and fifty was considered sufficient to elicit the needed responses from the participants, especially given the objectives of the study. Sufficient sample size is the minimum number of participants required to identify a statistically significant difference if a difference truly exists (Burmeister \& Aitken). Besides, Ali (2010), citing the work of Davies, Williams and Yanchar (2004), suggested that the researcher should decide on an appropriate size for sample depending on the research topic, population, aim of the research, analysis techniques, sample size in similar research, the 
number of the subgroups in the sample. Questionnaires were used - but not other data collections tools such as interviews, observation, and so on because of the objectives of the study as well as the approach adopted by the study. Professional teachers are the category of teachers who have received certificates of recognition as qualified to teach. Non-professional teachers, or pupil teachers, as they are generally known in Ghana, are not professionally trained, but have been engaged by the GES, either temporarily or permanently, to provide teaching services. Nonprofessional teachers were also considered for the study because either all or some of them will have also wanted to go for further studies so as to become professionals in the teaching job.

\section{Instruments and Reliability}

$\mathrm{Ho}$ and $\mathrm{Au}$, (2006), Teaching Satisfaction Scale (TSS) that was developed to specifically measure the JS of teachers of diverse sectors, was adopted to measure the JS of teachers. Even though there are other JS tools such as the one conceptualized by TALIS (2018) with subscales as "Teachers' job satisfaction with work environment" (JSENV), "Teachers job satisfaction with their profession" (JSPRO), and their "job satisfaction with target class autonomy" (JSTCA). Ho and Au (2006) TSS captures almost all the facets of the Teacher JS and, therefore, was adopted for the study. The scale which measures five different aspects of the JS construct, contains five items, with sample questions such as; 1. My conditions of being a teacher are excellent. 2, In most ways, being a teacher is close to my ideal. The TSS recorded an Alpha Correlation Coefficient (ACC) of .77. Reliability was also conducted to assess the scale's internal consistency and an ACC of .79 was achieved, which is an acceptable degree of reliability (Fraenkel \& Wallen, 2006). The questions were answered on a five-point Likert scale, with anchors of 1 strongly disagree to 5 strongly agree.

There are several scales developed from different models to explain teachers' ToI. Prominent among them include Job Resources-Demands (JD-R) and psychological capital' (personal resources), which include facets such as efficacy, optimism, hope and resiliency that may act as a buffer between contextual demands and turnover intention (Bothma \& Roodt, 2013). However, a five-item ToI scale developed by Wayne, Shore, \& Liden (1997) was adopted to measure the ToI of teachers in this study. The scale is an extended version of the ToI instrument by Landau \& Hammer, (1986), with the inclusion of specific timelines on employees' intention to leave their organisations; making it more preferable over other scales. The instrument has an ACC of .89 and has been used by researchers such as Villanueva \& Djurkovic, (2009). In this current effort, reliability was estimated as $\alpha=.72$. The items of the questionnaire were modified for reasons of clarity and to adapt to the context of our study. Teachers answered questions on a seven-point Likert scale, with anchors ranging from of 1 Strongly Disagree to 7 Strongly Agree.

\section{Data Collection and Analysis}

The study was cross-sectional in nature. Crosssectional studies, also known as one-shot or status studies, are the most commonly used design in the social sciences. This design is best suited to studies aimed at investigating the prevalence of a phenomenon, situation, problem, attitude or issue, by taking a cross-section of the population. They are useful in obtaining an overall 'picture' as it stands at the time of the study (Kumar, 2011). Of the 150 participants whose consent were sought and administered with 150 questionnaires, 116 of the questionnaires were returned usable, representing a response rate of $79 \%$. The number of respondents and the percentage score for each item in the questionnaire were computed, as well as the overall mean score for both JS and the ToI scales. To confirm whether EQ will moderate JS and ToI relationship, A PROCESS macro (Hayes, 2018 v. 3.4) was run, with mean cantering and 5000 bootstrapping. For a variable to make a moderation effect between a predictor and an outcome variable, the inclusion of the interaction in the model should lead to a significant explanation in the outcome variance, better than without it (Dardas \& Muayyad, 2015). This is represented in the equation $y=b_{01}+b_{1} X+$ $b_{2} M+b_{3} X M+e$; where $b_{3}$ is the interactive effect between JS and ToI. The predictors were 
first added in the first model, and with the inclusion of the interaction $b_{3}$ to determine whether the outcome variance after the inclusion will be significant. Statistical Package for Social Sciences (SPSS) version 21.0 for windows was used to analyse the valid data collected. Model diagnostic tests (normality, linearity and test of independence) were performed to attach credibility to the results.

\section{Results}

The demographic characteristics of the participants were analysed but because the results of an analysis do not contribute to the achievement of the objectives of this study, we decided not to report it. Therefore, we started by presenting the mean scores of teachers JS items (Table 1).

\section{Table 1: Percentages and Mean Scores of Teachers' Job Satisfaction Items}

Note: $S D=$ Strongly Disagree, $D A=$ Disagree, $U D=$ Undecided, A=Agree, $S A=$ Strongly Agree .

\begin{tabular}{|c|c|c|c|c|c|c|c|}
\hline Item & $\mathrm{SD} \%$ & DA \% & UD\% & A\% & SA\% & Mean & SD \\
\hline $\begin{array}{l}\text { In most ways being a teacher is close } \\
\text { to my ideal }\end{array}$ & $12(10.3)$ & $14(12.1)$ & $7(6.0)$ & $59(50.9)$ & $24(20.7)$ & 3.6 & 1.2 \\
\hline $\begin{array}{l}\text { My conditions of being a teacher are } \\
\text { excellent }\end{array}$ & $28(24.1)$ & $32(27.6)$ & $12(10.3)$ & $30(25.9)$ & $14(12.1)$ & 2.7 & 1.4 \\
\hline I am satisfied with being a teacher & $22(19.0)$ & $25(21.6)$ & $6(5.2)$ & $45(38.8)$ & $18(15.5)$ & 3.1 & 1.4 \\
\hline $\begin{array}{l}\text { So far, I have gotten the important } \\
\text { things I want to be as a teacher }\end{array}$ & 11(11.2) & $34(29.3)$ & $18(15.5)$ & $36(31.0)$ & $15(12.9)$ & 3.1 & 1.3 \\
\hline $\begin{array}{l}\text { If I could choose my career again, I } \\
\text { will change almost nothing }\end{array}$ & $34(29.3)$ & $20(17.2)$ & $12(10.3)$ & 25(21.6) & $25(21.6)$ & 2.9 & 1.6 \\
\hline
\end{tabular}

Overall Mean

$3.1 \quad 1.1$

Source: Field Survey (2020)

Table 1 presents percentages and mean scores of items of teachers' JS in the Tamale Metropolis. Of the 116 respondents $83(59+24)$ of them, representing $71 \%$ agree that the teaching profession is close to their ideal job, whilst 26 (12 +14 ) of them representing $22.4 \%$ disagreed. A few $(6 \%)$ of the teachers were undecided. When the respondents were asked to indicate their evaluation of the item "my condition of being a teacher is excellent", $44(30+14)$ representing $38 \%$ responded in the affirmative, whilst $12(10.3 \%)$ respondents were undecided, with $60(32+28)$ or $51.7 \%$ disagreeing. Regarding the statement "I am satisfied with being a teacher", 47 of the respondents (40\%) agreed, whilst $63(54.3 \%)$ disagreed. The rest (6 or 5.2\%) were undecided. Again, $45(11+34)$ of the respondents representing $40.5 \%$ disagreed with the claim that "they have gotten the most important things they want as teachers", whilst $51(44.8 \%)$ of the respondents agreed, $18(5.5 \%)$ of them were undecided. Finally, $50(43.2 \%)$ respondents accepted the statement "if I could choose my career again, I will change almost nothing", whilst 54 (46.5\%) respondents disagreed, $12(10.3 \%)$ of them were not sure. The overall mean score of teachers' JS is $\mathrm{M}=3.1, \mathrm{SD}=1.1$ 
Table 2: Percentages and Mean Scores of Teachers' Turnover Intention Items

Note: $S D=$ Strongly Disagree, $M D=$ Moderately Disagree, $S L=$ Slightly Disagree, $U D=U n d e c i d e d$, $S L A=$ Slightly Agree, $M A=$ Moderately Agree, SA=Strongly Agree .

\begin{tabular}{|c|c|c|c|c|c|c|c|c|c|}
\hline Items & SD & MD & SLD & UD & SLA & MA & $\mathbf{S A}$ & Mean & SD \\
\hline $\begin{array}{l}\text { As soon as I can find a } \\
\text { better job, I will leave } \\
\text { GES }\end{array}$ & $12(10.3)$ & $7(6.0)$ & $3(2.6)$ & $9(7.8)$ & $10(8.6)$ & $22(19.0)$ & $53(45.7)$ & 5.4 & 2.1 \\
\hline $\begin{array}{l}\text { I am actively looking } \\
\text { for a job outside GES }\end{array}$ & $17(14.7)$ & )$^{20(17.2}$ & $6(.2)$ & $18(15.5)$ & $11(9.5)$ & $24(20.7)$ & $20(17.2)$ & 4.2 & 2.1 \\
\hline $\begin{array}{l}\text { I am seriously thinking } \\
\text { of quitting my job }\end{array}$ & $33(28.4)$ & $33(28.4$ & $4(3.4)$ & $20(17.2)$ & $6(5.2)$ & $6(5.2)$ & $14(12.1$ & 3.1 & 2.1 \\
\hline $\begin{array}{l}\text { I often think of quitting } \\
\text { my job at GES }\end{array}$ & $38(32.8)$ & $20(17.2$ & $23(19.8)$ & $9(7.8)$ & $13(11.2)$ & $7(6.0)$ & $5(4.3)$ & 2.8 & 1.8 \\
\hline $\begin{array}{l}\text { I think I would be } \\
\text { working in GES in the } \\
\text { next five years. }\end{array}$ & $5(4.3)$ & $6(5.2)$ & $3(4.3)$ & $24(20.7)$ & $22(19.0)$ & $25(21.6)$ & $30(25.9)$ & 2.9 & 1.7 \\
\hline Overall Mean & & & & & & & & 3.7 & 1.4 \\
\hline
\end{tabular}

\section{Source: Field Survey (2020)}

Table 2 presents the results of the teachers' ToI in the Tamale Metropolis. In the table, it can be noticed that the majority $(73.3 \%)$ of respondents agreed with the statement that "As soon as I can find a better job, I will leave GES". Whilst $18.9 \%$ disagreed, a few $(7.8 \%)$ of them were undecided. Similarly, $32.1 \%$ of respondents disagreed when asked the statement "I am actively looking for a job outside GES". Whereas $15.5 \%$ of them were unsure what to say in response to that statement, almost half (47.4\%) responded in the affirmative. On the item "I am seriously considering quitting my job", $70(60.2 \%)$ respondents disagreed. Some $(22,5 \%)$ responded in the affirmative whilst the rest $(17.2 \%)$ were unsure what to say. Again, $81(69.8 \%)$ of the respondents disagreed with the statement "I often think of quitting my job at GES", 25(21.5\%) agre ed, and $9(7.8 \%)$ were undecided. On the statement "I think I will be working in GES in the next five years", more than half $(66.5 \%)$ of the respondents agreed, $14(13.8 \%)$ disagreed, whilst 24(20.7\%) were undecided. The overall mean score of teachers' ToI is presented as $\mathrm{M}=3.7, \mathrm{SD}=1.4$.

\section{Results of Multiple Regression model}

Table 4: Model summary

\begin{tabular}{lllllll}
\hline $\mathbf{R}$ & R-Sq & MSE & F & df1 & df2 & p \\
\hline .5314 & .2824 & 1.4960 & 14.6892 & 3.0 & 112.0 & .0000 \\
\hline
\end{tabular}

The results of the multiple regression analysis indicate a significant model $F(3,112)=14.689$, $p<.0001, R^{2,}=.284$ (Table 4). This means approximately $28 \%$ of the variability in teachers ToI is explained by the predictors (JS, EQ).
The result of the JS and ToI relationship $\left(X^{*} Y\right)$ is presented as: $b=-.6948, S E=.1057, p=.0001$, and EQ $(M)$ and ToI $(M * Y) ; b=2480, S E=1790$, $p=.1685$ (Appendix A). Thus, there is a significant 
effect of JS $(X)$ on ToI $(Y)$, whilst EQ $(M)$ is a nonsignificant predictor of ToI $(X)$ respectively. This means a unit percentage increase in teachers' JS will result in a $69 \%$ decrease in their intention to quit. The results of the int_1 show that the interaction is not statistically significant: $(b=$ $.2726, S E=1790, p=.1307)$. The results mean that EQ is not a significant moderator in the relationship between teachers' JS and their ToI. Consequently, the interaction or moderation effect is said to occur when the effect of the moderator in the relationship between the predictor variable and the outcome variable is statistically significant. The results also show $R^{2}$ change of .0148 after the inclusion of the interaction in the model and statistically non-significant interaction; thus, $p=$ .1307 (Appendix B).

\section{Discussion}

The main objective of the study was to examine the moderating role of teachers' EQ in their JS and ToI relationship. Among others, the study seeks to provide an important diagnostic assessment of the willingness of teachers to quit or to stay in their current profession in the Tamale Metropolis of the Northern Region of Ghana. On teachers' JS, it was observed that the majority ( $71 \%$ ) of the teachers in the Metropolis agreed that the teaching profession matches their life ideals and expectations, whilst $22 \%$ disagreed. although the respondents' assessment of their conditions as teachers were unspecified and discretionary, about half $(51 \%)$ of them believed that their general conditions of service as teachers were not excellent, whilst $38 \%$ of them held the opposite view.

Contrary to the researchers' expectation, the majority (54\%) of teachers said they were satisfied with their job as teachers, whilst $47 \%$ held a contrary opinion. Similarly, $44.8 \%$ of teachers in Metropolis agreed to have achieved the most important thing they want to be as teachers, and $45 \%$ disagreed. Whilst $43.2 \%$ of the teachers will choose to still be in the teaching profession, if given the opportunity to change profession, $46.5 \%$ of them said they will change profession as teachers. The findings, in general, revealed that the teachers in the Metropolis are moderately satisfied with their job, as the overall score $(M=3.1$, $S D=1.1)$ marginally exceeded the average.
Perhaps, the reason for this finding is the fact that the teaching profession allows teachers some time to engage in other income-generation activities which supplements their earning from the teaching job.

Teaching satisfaction is measured by the outcome of the discrepancy between what teachers want from the job and the current job offering. The findings suggest that there is a positive outcome between the job expectations of teachers in the Metropolis, and their current job conditions or realities. This finding lends credence to other findings (Chen, et al., 2014; Aydogdu \& Asikgil, 2011; Mburu, 2015) where teachers are found to be satisfied with their job to varying degrees.

On teachers ' intention to leave GES, the findings indicate that the majority (73\%) of teachers in the metropolis will leave GES as soon as they find a better job, whilst $43 \%$ will not leave GES even when they are presented with a better job. Again, it is said that about $47.4 \%$ of teachers in the Metropolis are looking for a job outside of GES, against $45 \%$ who are willing to stay with GES. More than half $(60.2 \%)$ of the teachers in the metropolis have reported that they are not seriously considering quitting GES, and $22.5 \%$ are seriously considering quitting. This is consistent with the finding that $69.8 \%$ of teachers in the metropolis do not often think about leaving GES, whilst $21.1 \%$ often think about leaving. These findings fit well with that of other researchers (Nick, Marcela, Marc, \& Danaher, 2019; Sergio, Martín, \& Natalio, 2020) whose works found teachers not wanting to quit their profession under the influence of certain incentives such as working environment, relationship with peers and time available in the teaching professional to engage in other worthwhile activities that are meant to enhance the teachers' life.

Responding to items regarding timelines within which teachers are intended to leave GES in the Metropolis, the findings indicate that most (66.5\%) teachers in the Metropolis hope to work with GES for some couple of years, whilst a few $(13.8 \%)$ of them are considering leaving GES. Some $(20.7 \%)$ of them were not sure whether to leave or stay with GES at the time of this study. The study, in general, found a low level of ToI among teachers in the metropolis, as the overall 
mean $(M=3.7, S D=1.4)$ is below the average. This finding is consistent with many other studies (Ali, 2008; Chen, et al., 2014; Aydogdu \& Asikgil, 2011; Mburu, 2015) that found that employees who are satisfied with their jobs are less likely to form an intention to quit their jobs.

It was also found that the JS of the teachers was significant but negatively related to their ToI in the Metropolis, given the effect size $(b=-.6948, p<$ .0001 ), hence we do not reject the $\mathrm{H}_{1}$. This means that a unit percentage increase in the JS of teachers in the metropolis will result in a decrease of approximately $69 \%$ in their intention to leave the GES, given the magnitude of the coefficient $(b)$. This finding confirms the research efforts of Aydogdu \& Asikgil (2011), and Mburu, (2015), as well as the normal work expectation that rational and "straight-thinking" employees will keep their jobs that yield maximum satisfaction and, therefore, will not give up or form an intention to quit their job.

The study also found no significant effect of teachers' EQ on their intention to quit GES ( $b=$ $.2480, p=.1680$ ), hence we do not accept the $H_{2}$. This finding means that teachers' EQ does not have any effect on their intention to quit GES. Teachers in the Metropolis' intentions to quit GES is, therefore. not a function of the type of degree they hold (or their EQ).

The study also found that the EQ of teachers in the Metropolis does not moderate the relationship between their JS and intention to leave GES, as the outcome variance was found statistically nonsignificant $\left(R^{2}\right.$ change $\left.=.0148, p=.13\right)$, therefore, we do not accept $H_{3}$. This means that at any level of teachers' EQ (Masters, first degree, diploma, and certificate), the relationship between their JS and intention to leave GES remains constant. In other words, the finding means that teachers' EQ has no effect on their intention to leave the GES. Therefore, the intentions of teachers to leave the GES do not depend on the type of degree they possess (or their EQ).

In normal organizational culture and practice, as employees rise higher on the academic scale and acquire more educational experiences, they expect more contingent rewards and compensations in the form of promotions and upgrades. Employees who receive a higher salary relative to their EQ are likely to be more satisfied with their jobs and, therefore, are less likely to look for alternative jobs (Cho \& Lewis, 2012). Similarly, the absence of adequate compensation that commensurates with their EQ is likely to result in a low JS, and the formation of an intention to quit their jobs for better alternatives. However, the evidence from the findings does not support the fact that changes in teachers' EQ affect their JS, and ultimately, their intention to leave GES for a better job elsewhere.

\section{Conclusion and Policy Implications}

The main objective of the study was to examine the moderation role of teachers' EQ in their JS and ToI relationship in the Tamale Metropolis in Northern Ghana. The findings revealed that teachers in the Metropolis were moderately satisfied with their job and have low levels of intention to quit their job. The study found a significant but negative relationship between teachers' JS and their intention to leave GES. Again, no significant effect was found between teachers' EQ and their intention to quit GES. The study's evidence also does not support the hypothesis that teachers ' EQ moderates their JS and ToI relationship in the Tamale Metropolis.

Empirically, the study contributes to the ongoing dialogue in the literature on employee JS and ToI relationship, by putting into perspective whether changes in EQ of teachers as a moderator, will significantly affect their job attitudes. The study provides counter-opinion on the public assertion that teachers in urban areas are not satisfied with their jobs, and have a high tendency to quitting their job.

After establishing a non-significant moderation effect, the results of the study provide a significant insight for policy reforms on teachers' further studies in GES and putting into perspective that increasing the number of teachers applying for further studies will not impact significantly on their intention to quit GES. The study also provides practical implication on personnel stability at the basic school level in the Metropolis, as organizations with satisfied employees and low levels of ToI are likely to experience stable personnel and human resource base for improved productivity. However, what is important to note 
is that further efforts in terms of policy reforms by the GES and other stakeholders to improve the general working conditions of teachers in the Metropolis are highly recommended to increase employee satisfaction in the teaching profession. This study has several limitations that should be addressed in future lines of research. First, the study was limited to basic school teachers in an urban area (the Tamale Metropolis), and may not reflect the views of teachers in rural Ghana. Future studies should, therefore, be directed to teachers at the higher educational level, as well as to teachers in rural Ghana. Secondly, the study was purely quantitative, so a mixed or qualitative method is recommended in future studies for a better understanding of the subject.

\section{References}

Abdul Rahman, S. M., \& Ramay, M. I. (2008). Measuring Turnover Intention: A Study of IT Professionals in Pakistan. International Review of Business Research Papers, 4(3), 45-55.

Abukari, A. K., Sanyare, F. N., \& Ibrahim, A. (2019). Exploring Job Satisfaction and Organizational Commitment Relationship:

A Study of Key Employee Groups in a Multi-Campus Public University in Northern Ghana. Researchjournali's Journal of Human Resource, 7(6), 1-16.

Afebia, C. A. (2016). Assessment Of Turnover Intentions And Employee Commitment Among Teachers Of The Ghana Education Service In The Bolgatanga Municipality. Unpublish Dissertation University of Ghana.

Agomah, A. C. (2016). Assessment Of Turnover Intentions And Employee Commitment Among Teachers Of The Ghana Education Service In The Bolgatanga Municipality. Accra: Unpublished Dissertation - University of Ghana.

Ali, D. (2010). The Sampling Issues in Quantitative Research. Educational Sciences: Theory \& Practice, 1-18.
Ali, N. (2008). Impact of Job Satisfaction on Turnover Intention: An Empirical Evidence. Journal of Managerial Sciences, 23-41.

Appiah-Agyekum, N. N., Suapim, R. H., \& Peprah, S. O. (2013). Determinants of Job Satisfaction among Ghanaian Teachers. Jouurnal of Education and Practice, 4(3).

Arshad, H., \& Puteh, F. (2015). Determinants of Turnover Intention among Employees. Journal of Administrative Science, 12, 115.

Aydogdu, S., \& Asikgil, B. (2011). An Empirical Study of the Relationship Among Job Satisfaction, Organizational Commitment and Turnover Intention. International Review of Management and Marketing, 1(3), 43-53.

Bothma, F., \& Roodt, G. (. (2013, November 01). The validation of the turnover intention scale. SA Journal of Human Resource Management, 11, 1-12.

Burmeister, E., \& Aitken, L. M. (n.d.). Retrieved May 6, 2021, from https://core.ac.uk/download/pdf/14387028 6.pdf

Chen, M.-L., Su, Z.-Y., Lo, C.-L., Chiu, C.-H., Hu, Y.-H., \& Shieh, T.-Y. (2014). An empirical study on the factors influencing the turnover intention of dentists in hospitals in Taiwan. Journal of Dental Sciences, 9, 332-344.

Cherng, G. D., \& Chieh-Peng, L. (2006, December 22). Comparing the effects of determinants of turnover intentions between Taiwanese and U.S. hospital employees. Human Resource Development Quarterly, 17(4), 403-421.

Chittipa, N., Phattarapon, O., \& Kijboonchoo, T. $(2012,12)$. Determinant Factors of Turnover Intention: A case study of Air Conditioning Company in Bangkok, Thailand. nternational Conference on 
Trade, Tourism and Management

(ICTTM'2012), (pp. 21-22). Bangkok

(Thailand).

Cho, Y. J., \& Lewis, G. B. (2012). Turnover Intention and Turnover Behaviours: implication for Retaining Federal Employees. Review of Public Personnel Administration, 32(1), 4-23. Retrieved from DOI: 10.1177/0734371X11408701

Cobbold, C. (2015). Solving the Teacher Shortage Problem in Ghana: Critical Perspectives for Understanding the Issues. Journal of Education and Practice, 9.

Cronley, C., \& Kim, Y. K. (2017, April 3). Intentions to turnover: Testing the moderated effects of organizational culture, as mediated by job satisfaction, within the Salvation Army. Leadership \& Organization Development Journal,, 38(2), 194-209.

Dardas, L. A., \& Muayyad, M. A. (2015). For fathersraisingchildrenwithautism,docopin gstrategies mediate ormoderatetherelationshipbetweenparenti ng stress and qualityoflife? Research inDevelopmentalDisabilities, 36, 620-629.

Ekabu, P. K. (2019). The Level of Remuneration and Turnover Intention of Public Secondary School Teachers in Meru County: A Mixed Method Study. European Scientific Journal, 15(13). doi:10.19044/esj.2019.v15n13p1

Finster, M. P. (2013). Teachers' Job Satisfaction, Organizational Commitment, Turnover Intentions, and Actual Turnover: A Secondary Analysis using an Integrative Structural Equation Modeling Approach. unpublish dissertation - University of Washington.

Fraenkel, J. R., \& Wallen, N. E. (2006). How to Design and Evaluate Research in Education (7th ed.). Nwe York: McGrawHill.
GNAT, \& TEWU. (2009). Teacher Attrition in Ghana; Results of a Questionnaire Survey. Ghana Education Service (GNAT).

Griffeth, R. W., \& Hom, P. W. (1988). A comparison of different conceptualizations of perceived alternatives in turnover research. Journal of Organizational Behaviour, 9, 103-1 I I1.

Hayes, A. F. (2018). Introduction to Mediation, Moderation and conditional Process Analyss- A Regression-Based Approach (Second ed.). New York, United States: The Guilfor Press.

Ho, C.-L., \& Au, W.-T. (2006). Teaching Satisfaction Scale; Measuring Job Satisfaction of Teachers. ucational and Psychological Measurement, 66(1), 172185. doi:10.1177/0013164405278573

Hoppock, R. (1935). Job Satisfaction (1st Edition ed.). New York: Harper.

Kafumbu, F. T. (2019). Job Satisfaction and Turnover Intention in Malawi: AQuantitative Assessment. International Journal of Educational Reform, 28(2), 207-226. doi:10.1177/1056787919841501

Kosi, I. K., Ibrahim, S., Janet, S. B., \& Mensah, R. (2015, May). Teacher motivation and job satisfaction on intention to quit: An empirical study in public second cycle schools in Tamale metropolis, Ghana. International Journal of Scientific and Research Publications, 5(5), 1-7.

Kumar, R. (2011). Research Methodology, a stepby-step guide for beginners. New Delhi: Sage Publications.

Landau, J., \& Hammer, T. H. (1986). Clerical Employees' Perceptions Of Intraorganizational Career Opportunities. Academy of Management /ournai, 29(2), 385-404. 
Lee, C.-C., Huang, S.-H., \& Zhao, C. Y. (2012). A Study On Factors Affecting Turnover Intention Of Hotel Empolyees. Asian Economic and Financial Review, 2(7), 866-875.

Macdonald, S., \& Maclntyre, P. (1997). The Generic Job SatisfactionS cale: Scale Development and Its Correlates. Employee Assistance Quarterly, 13(2).

Mburu, N. A. (2015). Impact Of Job Satisfaction On Turnover Intentions Among Teachers In Public Secondary Schools In Gatanga District, Murang'a County, Kenya. unpublish Dissertation - Kennyatta University.

Michaels, C. E., \& Spector, P. E. (1982). Causes of Employee Turnover: A Test of the Mobley, Griffeth, Hand, and Meglino Model. Journal of Applied Psychology, 67(1), 53-59.

Nick, K., Marcela, C., Marc, C., \& Danaher, P. A. (2019, March). Early career teachers' intentions to leave the profession: The complex relationships among preservice education, early career support, and job satisfaction. Australian Journal of Teacher Education, 44(3), 1-21.

Peter, W. H., Thomas, W. L., Jason, D. S., \& John, P. H. (2017). One Hundred Years of Employee Turnover Theory and Research. Journal of Applied Psychology, 102(3), 530-545.

Pienaar, J., Sieberhagen, C., \& Mostert, K. (2007). Investigating Turnover Intentions by Role Overload, Job Satisfaction and Social Support Moderation. SA Journal of Industrial Psychology, , 62-67.

Prasadini, N., \& Gamage, B. K. (2013, September). Job Satisfaction and intention to Leave of IT Professionals in Sri Lanka. Asia Pacific Journal of Marketing \& Management Review, 2, 1-11.
Quan, J., \& Cha, H. S. (2010, November). IT certifications, outsourcing and information systems personnel turnover. Information Technology \& People, 330351.

Reukauf, J. A. (2018). The Correlation Between Job Satisfaction and Turnover Intention in Small Business. unpublish dissertation Walden University.

Sam, F. K., Effah, B., \& Osei-Owusu, B. (2014). Exploring issues of teacher retention and attrition in Ghana: A case study of Public Senior High Schools in Kwabre East district of Ashanti region-Ghana. Journal of Education and Practice, 5(1).

Sergio, M.-L., Martín, S.-G., \& Natalio, E. (2020, April 24). Leaving the Teaching Profession: Examining the Role of Social Support Engagement and Emotional Intelligence in Teachers' Intentions to Quit. Psychosocial Intervention, 1-10.

Sottie, E. E. (2019, August 04). High annual attrition rate of teachers worrying GNAT. Retrieved from Graphic Online: https://www.graphic.com.gh/news/educati on/high-annual-attrition-rate-of-teachersworrying-gnat.html

Spector, P. E. (1985). Measurement of Human Service Staff Satisfaction; Development of the Satisfaction Survey. American Journal of Community Psychology, 13(6).

Tian-Foreman, W. (2009, October). Job satisfaction and turnover in the Chinese retail industry. Chinese Management Studies, 3, 356-378.

Villanueva, D., \& Djurkovic, N. (2009). Occupational Stress and Intention to Leave Among Employees in Small and Medium Enterprises. International Journal of Stress Management, 16(2), 124-137.

Voelck, J. (1995). Job satisfaction among support staff in Michigan academic librarie. 
College \& Research Libraries, 56(2), 157-170.

Wayne, S. J., Shore, L. M., \& Liden, R. C. (1997). Perceived Organizational Support And Leader-Member Exchange: A Social Exchange Perspective. Academy of Manage-ment Journal, 40(1), 82-111.

Wilbur, R. L. (1985). Age, Education, Job Tenure, Salary, Job Characteristics, and Job Satisfaction: A Multivariate Analysis. Human Relations, 38(8), 781-791. doi:DOI: $10.1177 / 001872678503800806$
Wright, B., \& Davis, B. (2003). Job Satisfaction in the Public Sector; The Role of the Work Environment. American Review of Public Administration, 33(1), 70-90. doi:10.1177/0275074002250254

Yamazakia, Y., \& Petchdee, S. (2002). Turnover Intention, Organizational Commitment, and Specific Job Satisfaction among Production Employees in Thailand. Journal of Business and Management, 4(4), 22-38.

\section{Appendix A: Model 1}

\begin{tabular}{lllll}
\hline & Coeff. & Se & $\mathrm{t}$ & $\mathrm{P}$ \\
\hline Constant & 3.6948 & .1153 & 32.0421 & .0000 \\
JS & -.6937 & .1057 & -6.5649 & .0000 \\
EQ. & .2480 & .1790 & 1.3859 & .1685 \\
Int_1 & -.2726 & .1790 & -1.5223 & .1307 \\
\hline
\end{tabular}

Note: $J S=J o b$ Satisfaction, $E Q=$ Educational Qualification. $\quad$ Source: Field Survey (2020)

Appendix B: Model 2

\begin{tabular}{llllll}
\hline & $\mathbf{R}^{2-}$ chng & F & df1 & d1d2 & P \\
\hline $\mathrm{X}^{*} \mathrm{M}$ & .0148 & 2.3175 & 1.0 & 112.0 & .1307 \\
\hline
\end{tabular}

Source: Field Survey (2020) 